\title{
Olhos de inferno: a morte no Rei Édipo de Sófocles
}

\author{
ORDEP J. TRINDADE-SERRA \\ Departamento de Antropologia \\ Faculdade de Filosofia e Ciências Humanas \\ Universidade Federal da Bahia
}

\begin{abstract}
RESUMO: Os derradeiros versos do "Rei Édipo", de Sófocles, versos que se referem a um tópos consagrado, ocasionaram, através de uma paráfrase de Frínico, a criação do "mito". de Sófocles, cuja vida feliz a tradição consagrou como uma antítese do destino de seu personagem. O paradoxo desses versos, todavia, merece consideração mais profunda. Com efeito, em toda a tragédia a morte é representada de maneira paradoxal. Édipo faz a experiência de uma situação liminar em que morte e vida, cegueira e visão se confundem. Uma evidência disso é simbolicamente dada no verso 987 de Oedipus Rex. PALAVRAS CHAVE: Édipo, Sófocles, morte, simbolização da morte, tragédia.
\end{abstract}

Num artigo sobre a morte, não é despropositado começar pelo fim:

Habitantes de minha pátria Tebas, eis o Édipo

Que os famosos enigmas soube, o homem poderoso

Cuja sorte, na urbe, todos viam com inveja:

Vejam em que onda horrenda de desgraça afundou!

Assim, nenhum mortal que o último dia ainda

Está por ver, não felicitem antes

Que, sem prova de mágoa, chegue ao termo da vida. ${ }^{1}$

São as últimas palavras do drama, pelo menos na leitura mais aceita. O Corifeu as pronuncia diante da imagem terrível do rei que se retira, com os olhos ensangüentados, depois de separar-se, muito a contragosto, de suas filhas queridas, tomando o rumo do exílio: a imagem do "maior dos homens" 2 derruído, arrasado, mergulhado na miséria absoluta.

É a última cena da tragédia Rei Édipo.

Discute-se hoje se este final é inteiramente da lavra de Sófocles. Há quem ache que os versos 1526-30 correspondem a um acréscimo tardio, não sofocleano, em um manuscrito alterado. No entanto, parece-me mais segura a tese tradicional, que está muito bem argumentada, em breves termos, no famoso compêndio de Schmidt-Stählin (1934, p. 396), onde a passagem é assim comentada:

Der Schluss der Tragödie lässt Oedipus Zukunft völlig im dunkeln. Die trochäischer Tetrameter, die der Chor als epimythion beifügt, erscheinen uns vielleicht 
gemeinplätzig, sind aber kaum anzufechten. Vielmehr sind sie ganz ernst zu nehmen. Sie sagen schlicht und ehrlich was der Dichter mit dem Stücke wollte: nicht sagen, wie ein Frevler für reine Schuld gestraft wird, sondern wie auch der Beglückteste und Höchstausgesehene ohne sich eine Schuld bewusst zu sein, keinem Augenblick vor dem Sturtz in tifstes Ellend sicher ist.

Os eruditos apontam a correspondência entre os versos 1528-1530 de Oed. Rex, acima citados, e, por exemplo, os versos 100-102 da Andrômaca, de Eurípides. É claro que, no caso, ambos os trágicos se reportam a um tópos tradicional - o mesmo tópos que ilustra a famosa anedota de Sólon e Creso, narrada por Heródoto (I, 32).

Mas a história literária enriqueceu este elemento da tradição com um lance magnífico.

O dramaturgo ateniense Frínico, na sua perdida comédia As Musas, homenageou o grande poeta recém-falecido com versos nos quais dizia que Sófocles "viveu belamente, sem ter padecido nenhuma desgraça" (kalôs d' eteleútes' oudèn hypomeínas kakón). ${ }^{3} \mathrm{~A}$ sentença de Frínico (a qual sobreviveu à obra onde ela se inscrevia) parafraseia claramente os três últimos versos de Rei Édipo, e foi a origem de um outro lugar comum, repetido à saciedade em quase todos os escritos sobre Sófocles: projetou a imagem do "poeta feliz", através desse contraste com um seu personagem, o mais desgraçado...

Contudo, pouco se atentou para a ironia do motivo que assim enlaçou as figuras dos dois.

Essa ironia reside no paradoxo que o tópos sutilmente evocado por Frínico encerra. É que a sentença tradicional glosada por Sófocles, a rigor, coloca a felicidade humana num extremo inalcançável: ninguém pode ser felicitado, se a declaração de ventura tem de esperar o fim da vida do sujeito.

Terrível ironia, com efeito: um homem pode apenas ter sido feliz, quando já não é... sequer vivo; nem dirá, como Fernando Pessoa: "fui feliz outrora agora". Por outras palavras, "feliz" não há de dizer-se mortal nenhum, enquanto mortal: só uma vida extinta, a vida de um morto, talvez possa (mas raramente) ser assim considerada.

A injunção que a sentença implica evoca, possivelmente, um temor religioso: é este que inibe a declaração de felicidade pelo sujeito, porque encerraria qualquer coisa de hýbris, de desafio aos poderes supremos. Todavia, a reserva feita vai além desse temor. Ultrapassa-o quando inclui no seu raio de alcance todos os mortais — os outros também...

$\mathrm{Na}$ verdade, os últimos versos de Rei Édipo retomam e arrematam um tema desenvolvido no seu Quarto Estásimo. Basta recordar-lhe a primeira antístrofe
Ai, gerações dos mortais!
A sua vida tenho eu
Na conta de nada!
Pois quem, dentre os homens, tem
Mais do que a fama de feliz
- Um parecer, que desaparece?
Teu exemplo se considero,
Tua sina, Édipo,
Ó desditoso! Mortal nenhum
Digo ter dita, nunca mais.

Os versos derradeiros do drama trazem a conclusão deste arrazoado, arrematam a conclusão que o exemplo de Édipo suscita. $O$ arremate explicita a condição restritiva, rigorosíssima, para que se declare a felicidade de um homem: como se viu, a de que ele já tenha falecido, sem experimentar nada de doloroso, "sem prova de mágoa".

Pode-se aproximar esta conclusão de uma famosa sentença heracliteana (Fr. 25 D-K.):

Cabe a melhor sorte aos que tiveram a melhor morte. ${ }^{4}$ 
Sófocles toma como referência o mesmo limite; mas, ènquanto o critério de Heráclito para o reconhecimento da sorte melhor, a julgar pelo conteúdo explícito de sua sentença, é o da boa morte, nos versos sofocleanos esse juízo final considera claramente a totalidade da vida humana - apreciada desde seu termo.

De qualquer modo, este é apenas um dos aspectos do pensamento da morte no Rei Édipo, um pensamento que aí se exprime num discurso paradoxal, com marcas de enigma... Para mostrálo, convém evocar uma passagem decisiva do primeiro episódio: a cena do terrível agón que confronta o Rei de Tebas com o Profeta de Apolo. O soberano, surpreendido por uma referência a seus pais, indaga (v. 437):

\section{... Que mortais me deram vida?}

E o adivinho responde (v. 438):

Este dia te trará o nascimento e a morte.

Observa Édipo, então (v. 439):

Tudo o que fala é obscuro, enigmático!

O leitor ou espectador da tragédia, embora sabendo a que desgraças se refere Tirésias, sente-se inclinado a concordar com esta observação de seu antagonista. Pois a sentença deve cumprir-se, e cumpre-se. Mas como?

Édipo tem no mesmo dia a revelação do segredo de sua origem: deixando de ser o filho de Pólibo e Mérope, "renasce" como filho de Laio e Jocasta.

De certo modo, portanto, este dia efetivamente lhe dá o nascimento

E a morte?

Vejamos...

Depois da tremenda revelação, o herói, desesperado, irrompe de novo no palco, já transformado num cego sangrento, e o coro trava com ele um diálogo lancinante, em que termina por dizer ao desgrçado, no arrebato do kómmos (v. 1368):

\section{Melhor te fora a morte que esta vida de cego!}

Mas Édipo retruca com veemência, justificando sua atitude (isto é, o ter-se cegado). A discussão de algum modo envolve o espectador, que sente a mesma estranheza do coro: sente que Édipo eludiu a morte de uma forma horrível — e se pergunta por que ele o terá feito.

Mais tarde (v. 1149-54), o infeliz pede a Creonte que o envie para o Citerão, pois esta montanha seus pais lhe quiseram dar por tumba: pede a morte que os genitores lhe destinaram... Porém, mal acaba de formular este voto, o próprio herói diz (1455-7):

\section{E contudo bem sei que moléstia nenhuma}

Nem outra coisa pode aniquilar-me: outrora

Não fui salvo da morte senão pra grande horror.

O desgraçado afirma-se indestrutível...

Os comentaristas vêem nessa passagem uma alusão ao mito que Sófocles poetizaria em seu Édipo em Colono.

Por outro lado, ainda na tragédia aqui discutida, Sófocles põe na boca do herói outra afirmativa assombrosa: no seu apelo a Creonte para que tome conta de suas filhas, Édipo diz (1504-5):

$$
\text { ... pois nós, os que as geramos }
$$

\section{Morremos, todos dois...}

Ele não morreu, nada o pode aniquilar (1455-7); no entanto, está morto (1504-5). Sobrevive a si mesmo, na escuridão medonha, tendo-se cegado com as próprias mãos: um gesto, a rigor, suicida, de uma tremenda violência, que o reduz a uma vida miserável, condena-o a sofrimentos 
atrozes. Por que o fez? Não seria melhor que se matasse, de fato? É a dúvida do coro. Convém apreciar a resposta de Édipo (1372 sq.). Ela reúne três argumentos. Aqui está o primeiro: Édipo diz que, se ainda enxergasse, não sabe como fitaria seu pai e sua mãe... no Hades.

Por outro lado (eis o segundo argumento), ele não quer ver os filhos (cf. 1375-8):

E acaso contemplar a vista dada à luz

De filhos como os que gerei, daria gosto?

Ora, nunca, jamais, quando nada a meus olhos!

A terceira razão que o infeliz alega (1385) é a vergonha de ver-se mirado com escândalo pelos tebanos:

E então teria olhos de encarar esta gente?

Os dois primeiros motivos transcendem o respeito humano: o horror de seus atos faz com que Édipo queira, antes de mais nada, fugir à visão de suas vítimas, e à das vivas manifestações de sua abominação. Em todo caso, o primeiro argumento revela-se o mais extraordinário: $O$ herói involuntariamente criminoso cega-se para não enxergar, depois de morto, os pais defuntos...

Os comentaristas costumam explicar os versos 1372-4 evocando uma velha crença grega: a de que, nos Infernos, o indivíduo morto (ou antes, sua psykhé) mantém, in spectro, as mesmas características que tinha em vida, inclusive os traços físicos. ${ }^{5}$

Mas a contradição aguça o sentimento da excepcional desgraça do herói: ele quer furtarse à visão de fantasmas no reino do Invisível... Quer envolver-se em trevas impenetráveis às sombras do Inferno.

Esta passagem pode ser relacionada com outro trecho, muito discutido, da mesma tragédia: um trecho da fala do criado que, vindo do interior do palácio, relata ao Coro, no Êxodo, a morte de Jocasta e o autocegamento de Édipo (1268-1274):
Alfinetes de ouro tirando do vestido
Com que ela se arrumava, ele os ergueu pro alto
E pegou a ferir-se os globos de seus olhos
Aos brados de que assim já não veriam mais
No porvir os seus males, feitos nem padecidos -
Sós na treva com as vistas daqueles que não eram
De ver, e dos que quis, porém não conheceram.

Neste conjunto, os versos 1271-4 são os mais intrigantes e intrincados. Por conta da estrutura sintático-semântica que os caracteriza, no original, eles representam um grande desafio para os tradutores e intérpretes. Parece-me que foi Karl Reinhardt (1971) quem melhor os abordou, ao observar que a obscuridade sintática do grîphos neles encerrado é símbolo do complexo de cegueira e visão entrelaçados no destino de Édipo: referem o momento em que ele mergulha na escuridão "de corpo e alma", e em que principia sua visão verdadeira, um conhecimento do seio da treva do desconhecer - correspondente, como nota o grande intérprete, ao conhecimento de si mesmo.

Merece relevo a imposição que faz Édipo a seus olhos, quando os golpeia: a de reconhecer na treva, pela treva, o que os cegou na visão. Seus olhos, denuncia o pobre, erraram por excesso e falta, vendo os que não eram de ver (seus filhos-irmãos, dados à luz de modo indevido) e deixando - embora os tivessem visto - de fazer-lhe ver quem eram seus pais. Por isso, o miserável lhes impõe que fiquem, pro futuro, (sós) com essas vistas, agora conscientes... “...na treva".

O terrível jogo de treva-luz tem correspondência com a situação liminar de Édipo, o paradoxo em que ele tragicamente envolve morte e vida.

Em outro ponto desta mesma tragédia, uma imagem fúnebre toma o desenho de um foco 
luminoso, reveste a forma ocular.

Isto acontece no Terceiro Episódio, numa fala de Jocasta:

A rainha mandara chamar o esposo para que ele ouvisse do mensageiro coríntio a nova da morte de Pólibo. Édipo escuta a notícia, interroga o portador e, depois de convencer-se, proclama a caducidade dos oráculos, que lhe haviam predito o destino de parricida. Jocasta procura reforçar esta nova atitude cética do esposo, mas ele hesita ainda, ao lembrar-se de outra profecia: a de que estava destinado a casar-se com a mãe. Cf. o v. 976:

\section{E a cama da mãe, como não temerei?}

A rainha contraargumenta, dizendo que "de nada há previsão segura", e que muitos mortais, em sonhos, já se deitaram com a mãe, mas leva melhor vida quem não dá importância a semelhantes sonhos (enfim, quer dizer, "los sueños sueños son"... e as profecias lhes equivalem).

Todavia, Édipo ainda receia, pois Mérope está viva...

É então que Jocasta lhe faz uma réplica notável, no verso 987. Eu o traduzi assim:

Abre-te o olho a cova de teu pai: grande prova.

Ao pé da letra, seria de ler:

[Mas] na verdade (é) um grande olho a cova de teu pai.

Tournier (1866, p. 190) sugere que, neste verso 987, ophthalmós equivale a ópe, "fenestra, une ouverture par laquelle on voit, un jour"; e lembra que "la plupart des comentateurs interprètent: 'lux, i. e., solatium, levamen'."

O Lexikon Sophocleum, s. v., anota: “...figuratam lectionem semel habet [ophthalmós]...” e cita, a propósito, o referido verso, explicando: "'lux quasi vitam collustratura, i. e., levamen et solatium acceptum inde, quod metus parricidii sublatus erat."

O Liddel-Scott, s. v., anota o mesmo sentido figurativo de ophthalmós, citando também este mesmo verso de Sófocles... que é a base do registro.

No esforço de tradução, vali-me da expressão que temos em nossa língua "Abrir os olhos de alguém (para alguma coisa)". Acrescentei: "grande prova" " "grande, mégas, está no original), num desdobramento analítico do argumento, do conceito figurado: pois é claro que Jocasta está argumentando, e apresenta um sinal (um sêma... se me é permitido um jogo de palavras nesta argumentação - pois sêma, em grego, além de "signo" e "monumento", também significa "túmulo") da evidência de sua tese. Mas assim procedi também no interesse de ligações e ressonâncias com o verso seguinte: no original, mégas se repete aí (cf. v. 988), na resposta de Édipo. ${ }^{6}$

A frase em português pode enriquecer-se com uma ambigüidade que se acomoda à múltipla intenção de Sófocles.

Creio, com efeito, que o poeta jogou, então, com pelo menos dois sentidos...

Começarei por assinalar um elemento nuclear dessa constelação significativa. No centro, está a equação túmulo $=$ olho $($ táphoi $=$ ophthalmós $)$.

Todavia, a contexto dialógico - e, mais especificamente, o claro esforço conativo de Jocasta - orienta esta imagem na direção de seu interlocutor, dirige-a a ele, como um sinal que ele deve acolher, como coisa que lhe diz respeito. Assim, o leitor percebe logo que a rainha, ao dizer a Édipo: - "A cova de teu pai é um grande olho" - subentende: — "para ti".

De fato, como quer que se interpreta a expressão, o sinal da tumba, desse "olho" de extrema evidência, é inquestionavelmente dirigido a Édipo: o "alívio", ou o "testemunho evidente", decorre para, ou concerne a, ele; deve ser aferido, ou auferido, por ele. Trata-se, não há dúvida, de uma demonstração que lhe é feita. A rigor, essa imagem só tem sentido a partir daí. Indica um franquear... mas transposto este ato para um plano lógico. Fenestra, jour - diz Tournier. Por certo, é isso mesmo: abertura iluminante, iluminada, por onde alguém - o destinatário da argumentação - pode receber esclarecimento. Ophthalmós. 
Mas não se esqueça a terrível associação que liga ophthalmós, nessa frase, à cavidade sombria da tumba.

Até a disparidade com que o número gramatical desequilibra a equação acaba por reforçála, pois remete, ocultamente, a uma outra diferença, onde a metonímia desliza, a jogar também com o número. Onde nós dizemos "tumba" está um plural, táphoi, que entra em correspondência com o singular ophthalmós: o "olho" da metáfora, em cuja origem enxergamos... os olhos do homem.

Segundo é a clara intenção da rainha, o signo (o sêma, o monumentum) que ela, Jocasta aponta , deve tornar patente a Édipo algo que ele (aos olhos dela) precisa ver. Em vista disso, creio que não extrapolo quando traduzo (vou por partes, agora): "a cova de teu pai abre-te o olhos..." Mas é claro que esta frase tem duas leituras possíveis:

(1) "a cova de teu pai é um olho aberto para ti";

(2) "a cova de teu pai está a abrir teu olho".

Na primeira leitura, a significação ainda se biparte em duas possibilidades: um olho aberto para ser enxergado por $t i$; ou, ainda: um olho aberto para te enxergar (uma vigilante ameaça)... Creio que Jocasta diz também isto - sem que o pretenda, no chiaroscuro verbal da ironia trágica sofocleana. Ela pensa em Pólibo mas, tocados pela sombra sinistra de suas palavras, nós nos lembramos de Laio.

A segunda leitura ["a cova de teu pai está a abrir teu olho", isto é, "a fazer-te ver"] não se sustenta no arranjo sintático que tem a frase no original grego, mas sustenta-se de modo bem firme na estrutura pragmática do diálogo de que o verso em questão é parte: traduz o conato de sua enunciação.

A maior parte dos tradutores passa ao largo desta metáfora terrível, ou a simplifica Assim verte Mazon (cf. Dain \& Mazon, 1981):

C'est un immense allègement pourtant que de savoir ton père dans la tombe.

Gama Kury (1990):

De qualquer modo, é grande alívio para ti

Saber que teu pai está no túmulo.

Storr (1956):

And yet thy sire's death lights our darken much.

Jebb (1952):

Howbeit thy father's death is a great sign to cheer us.

Jaime Bruna (1964):

Não obstante, a tumba de teu pai é uma grande luzerna.

Errandonea (1959):

Si, buen argumento el sepulcro de tu padre.

Roussos (1993):

O táphos tou gonioú méga semádi.

Mesmo Hölderlin, neste caso, ousou pouco: cf. Hölderlin, 1965:5:183:

Jedoch ein gross Licht ist des Vaters Grab dir.

Devo defender minha opção.

Primeiro, recordarei que os sentidos derivados de ophthalmós são derivados. Ir à primeira raiz da imagem é pelo menos justo.

Segundo, a correspondência subliminar que acima se apontou entre uma diferença patente na equação, no que tange ao número gramatical, e uma metonímia latente, mas ineludível, dá 
sinal da operação de uma analogia muito poderosa. Aliás, nesta mesma tragédia temos um canto em que a metáfora "fechar os olhos" = "(fazer ) morrer" ganha uma densidade incomum: o final do Quarto Estásimo (versos 221-222).

A ligação analógica entre "olho" e "cova" passa certamente pela idéia dos movimentos opostos de abrir/fechar, associada com a de manifestação/ocultação, no jogo de treva/luz, morte/ vida, tão importante no Rei Édipo. Por outro lado, a cavidade do olho é ressaltada como um foco simbólico, nestra tragédia, de uma forma violenta, sinistra: o herói perfura, "escava" os próprios olhos - e assim fecha sua visão.

A idéia de fechar-se com a cegueira, fechar-se pela barragem dos sentidos, é explicitada no seu discurso: cf. os versos 1386-1390, onde Édipo exprime o desejo de se tornar também surdo, para assim encerrar-se completamente no seu corpo ocluso. Ele ficaria surdo represando, se pudesse, a fonte da audição... Recorde-se que, na perspectiva dos antigos helenos, na imagem que eles se faziam tradicionalmente da fisiologia dos sentidos, visão e audição tinham, por assim dizer, uma energia ativa: nessa perspectiva, uma luz interna anima os olhos, brota deles, assim como, segundo bem o revela o verso sofocleano citado, a "corrente da audição" "mana" dos ouvidos, donde vai ao encontro da sonoridade externa. Édipo deseja represá-la para fechar-se, cortando esta comunicação com o mundo; quer encerrar-se no corpo como em um cárcere, ou em um túmulo. Por analogia com a idéia expressa nesse voto desesperado, compreende-se a sua percepção da própria cegueira: perfurando os olhos, ele quis fechar as vistas. Para confirmá-lo, relacione-se este ponto com versos 1271-4, acima comentados: percebe-se então que Édipo aí condena seus olhos (quando os fura) a encerrar-se na escuridão com as imagens "internas" dos que quisera ter reconhecido e dos que não devia ter visto.

No que toca ao verso 987, traduzindo ophtalmós por "luzerna", toma-se um dos lados da metáfora, mas deixa-se outro, muito importante na economia simbólica não só desta frase capital, mas da obra como um todo. E apaga-se a ironia trágica. Traduzindo “... é um grande alívio", simplesmente elimina-se a imagem. Acho importante manter, na busca do contacto, em nossa língua, com o texto da tragédia, o lugar cavo desse olho tenebroso cuja evidência Jocasta assinala cegamente, prolongando em seu vazio o ser/parecer equívoco do pai de Édipo, de seu filho/ marido: do olho que pre-vê a escuridão mortal sobre a rainha, ainda empenhada em negar as previsões.

\section{Notas}

1 - Cf. Soph. Oed. Rex, 1254-30. Exceto quando houver indicação em contrário, as citas de Rei Édipo são de minha tradução, ainda inédita.

2 - Cf. v. 31-4, onde o sacerdote de Zeus diz a Édipo que os tebanos (representados por ele e pelo coro) não o igualam aos deuses, mas o consideram "o primeiro dos homens".

3 - Phr. Frag. 31 Kock.

4 - Tradução de Eudoro de Sousa (1978, p. 18).

5 - Mas é impossível não recordar aqui uma outra situação mítica na qual se supõe o oposto, também paradoxalmente: refiro-me a uma passagem da Nekuya (cf. Hom. Od. XI, 90-91) em que Odisseu narra como, consumado o sacrifício das vítimas consagradas aos deuses infernais, ele não deixa os mortos virem beber-lhes o sangue, até que Tirésias acorra. Por fim, 
Ao que parece, a sombra do adivinho cego "vê", reconhece o herói antes que este lhe dirija a palavra. Mas Tirésias tem o privilégio de ser, nos infernos, a única alma clarividente...

6 - "Grande, sim; eu, porém, tenho medo da vida."

\section{Referências Bibliográficas}

BRUNA, J. (trad.). “Rei Édipo”. In: BRUNA, J. O Teatro Grego. São Paulo, Cultrix, 1964. p. 43-68.

DAIN, A. \& MAZON, P. "Oedipe Roi”. In: DAIN, A. \& MAZON, P. Sophocle. (T.II. Ajax Oedipe - Electre). Paris: Les Belles Lettres, 1981.

ELLENDT, F. \& GENTHE, H. Lexikon Sophocleum. Hildesheim: Georg Holms Verlagsbuchhandlung, 1965.

ERRANDONEA, I. , S. J. Sófocles. Tragedias. Barcelona: Ed. Alma Mater, 1959.

GAMA KURY, M. da. (trad.). : "Édipo Rei”. In: GAMA KURY, M. da. Sófocles. A Trilogia Tebana. Édipo Rei - Édipo em Colono - Antígona. Rio de Janeiro: Zahar, 1991. p. 19-99.

HÖLDERLIN, F. (trad.). "Oedipus der Tyran”. In: Hölderlin Sämtliche Werke, herausgegebene von Friedrich Beissner. Fünfer Band - Übersetzungen. Stuttgart: W. Kohlhammer Verlag, 1965, p. 145-210.

JEBB, Sir R. C. (trad). “Oedipus the King”. In: Great Books of the Western World, vol. 5. Chicago/ London/Toronto/Geneva: Encyclopaedia Britannica, Inc., 1952.

KOCK, T. Comicorum Graecorum Fragmenta. Leipzig: B. G. Teubner, 1880-1888.

LIDDEL, H. G. \& SCOTT, R. A. Greek - English Lexikon. Oxford: Clarendon Press, 1940.

REINHARDT, K. Sophocle. Paris: Éditions de Minuit, 1971.

ROUSSOS, T. (trad). Sophokles. Oidipous Tyrannos. Athena: Kartos, 1993.

SCHMIDT, W. \& STÄHLIN, O. Geschichte der Griechische Literatur. Erster Teil. Zweiter Band. München: C.H. Beck' sche Verlagsbuchhandlung, 1934.

SOUSA, E. de. Filosofia Grega. Brasília: Editora Universidade de Brasília, 1978.

STORR, F. (trad.).Sophocles. London: William Heinem Ltd., 1956.

TOURNIER, E. (ed.). Les Tragédies de Sophocle. Paris: Hachette, 1866.

TRINDADE-SERRA, Ordep J. Les Yeux d'Enfer: La Mort dans l'Oedipe Roi de Sophocle. Classica, São Paulo, 7/8: 75-82, 1994/1995.

RÉSUMÉ: Les derniers vers de l'Oedipe Roi, de Sophocle, qui se rapportent à un tópos traditionnel, ont occasionné, à travers une paraphrase de Prinique, la création du "mythe" de Sophocle, dont la vie heureuse a eté célebrée par la tradition comme l'antithèse du destin d'Oedipe. Toutefois, le paradoxe de ces vers mérite une considération plus approfondie. En effect, dans cette tragédie toute entière la mort est représentée d'une façon paradoxale. Oedipe fait l'expérience d'une situation liminaire où mort et vie, cécité et vision se confondent. Le symbolisme du vers 987 de l'Oedipe Roi le démontre.

MOTS CLÉS: Oedipe, Sophocle, mort, symbolisation de la mort, tragédie. 